\title{
TITLE
}

\section{Exploring Preceptorship Programmes: Implications for Future Design}

\section{ABSTRACT}

- Aims and objectives: To review and analyse current preceptorship programmes within NHS trusts in the North West of England. To evaluate the pedagogic rigour of the programme and suggest recommendations to inform the future design of preceptorship programmes.

- Background: Enhancing the retention of newly qualified staff is of particular importance given that the journey from a new registrant to a competent healthcare professional poses a number of challenges, for both the individual staff member and organisations.

- Design: A mixed methods evaluative approach was employed, using online questionnaires and content analysis of preceptorship documentation.

- Methods: Forty-one NHS trusts across the North West region employing newly qualified nurses were invited to participate in the completion of an online questionnaire. In addition, preceptorship programme documentation was requested for inclusion in the content analysis. This study utilised the SQUIRE (Standards for Quality Improvement Reporting Excellence) guidelines.

- Results: The response rate for the questionnaire was $56.1 \%(n=23)$. Eighteen trusts (43.9\%) forwarded their programme documentation. Findings highlighted the wide variation in preceptorship programmes across the geographical footprint.

- Conclusions: There were instances of outstanding preceptorship and preceptorship programmes where there was a clear link between the strategic vision, i.e., trust policy, and its delivery, i.e. preceptorship offering. There was no one framework that would universally meet the needs of all trusts, yet there are key components which should be 
included in all preceptorship programmes. Therefore, we would encourage innovation and creativity in preceptorship programmes, cognisant of local context.

Relevance to clinical practice: The significant shortage of nursing staff in England is an ongoing issue. Recruitment and retention are key to ameliorating the shortfall, and formal support mechanisms like preceptorship, can improve the retention of newly qualified staff. Understanding current preceptorship programmes is an important first step in establishing the fundamental building blocks of successful preceptorship programmes and enabling the sharing of exemplary good practice across organisations.

KEYWORDS: nursing staff, preceptorship, attrition, retention, personnel turnover, supply-demand, clinical competence, survey, new registrants, North West England

What does this paper contribute to the wider global community?

- This paper highlights the importance of preceptorship as a means to increase the retention of newly qualified nurses, and its pertinence in the current workforce and demographic climate.

- An overview of existing preceptorship programmes and practice in the North West of England is provided, and instances of excellent practice identified.

- The key building blocks required to produce a good preceptorship programme are established, and recommendations given for implementation 


\section{INTRODUCTION}

Enhancing the retention of newly qualified staff is of particular importance given that the journey from new registrant to competent healthcare professional presents a number of challenges, both for the individual staff member and for the organisation. For example, the 'reality shock' associated with moving from student to new registrant is well documented (AlDossary, Kitsantas, \& Maddox, 2014; Chandler, 2012; Rush, Adamack, Gordon, Lilly, \& Janke, 2013). Further, there is complexity for the organisation in developing innovative and diverse strategies to meet the challenge of retaining new registrants. Evidence suggests preceptorship programmes are a key factor in achieving this, and can have a positive impact on the attrition rates of newly qualified staff attrition (Hamshire, Spearing, \& Wibberley, 2014). The Nursing and Midwifery Council (NMC) defines preceptorship as a period to guide and support all newly qualified practitioners to make the transition from student, and to develop their practice further (Nursing and Midwifery Council, 2006).

Responsibility for ensuring the health workforce has the right skills, behaviours and training available to support the delivery of excellent healthcare and health improvement resides with Health Education England (HEE). HEE is a non-departmental government body working nationally and locally to support the implementation of high quality, effective and compassionate care. Locally HEE is operationalised across geographical regions, of which the North West is one. This is a large and diverse region extending across Cumbria, Lancashire, Cheshire, Merseyside and Greater Manchester. Recognising there was a need to explore and understand the multiple issues that affect recruitment and retention of nurses and midwives, HEE in the North West established a broad strategic programme of work to explore this area. One fundamental aspect of this work was to understand the current preceptorship offering across the region, and a second aspect was to explore the possibilities of devising a standardised approach that could be of benefit to all trusts in aiding retention. The University was commissioned by HEE to establish the range and content of preceptorship programmes being offered across the North West region, and to investigate the possibility of 
establishing a robust model or framework that may enhance staff retention in the workplace. This paper outlines the findings and recommendations of this work. Whilst this study was undertaken in North West England, the research has wider utility nationally and internationally, to inform the development of new preceptorship programmes for nurses and other diverse healthcare disciplines.

\section{BACKGROUND}

In the United Kingdom there are estimated to be more than 600,000 nurses working within the combined NHS, and social care and independent health sectors, and of these approximately 361,000 nurses work in the NHS in England (Migration Advisory Committee, 2016). Although this represents an increase in nurse numbers over the past three years, there is still a significant shortfall of skilled nurses within the NHS. Recent evidence suggests that $93 \%$ of NHS trusts are experiencing an acute shortage of registered nurses (NHS Employers, 2015), however, accurate and detailed information on vacancy rates is difficult to find, and central collection of these data ceased in 2010 . The Royal College of Nursing has repeatedly called for the Department of Health to recommission these data to underpin workforce planning, and in its 2017 report, 'Safe and Effective Staffing: the Real Picture' it resorted to a freedom of information request to obtain the data. Reported vacancy rates varied from 5.6$18 \%$ across England, with an average of $16 \%$, and in the North West region reported vacancy rates were $8.1 \%$.

Historically, the supply of nursing staff has consistently failed to keep pace with demand and consequently staff retention is, and has been, a fundamental priority for many NHS trusts (Phillips, Kenny, Esterman, \& Smith, 2014), Trusts are organisations within the English NHS which deliver aspects of healthcare to a geographical area, including specialised functions such as the ambulance service. Supply and demand factors have similarly both contributed to the current nursing shortage (Marangozov, Williams, \& Buchan, 2016) and warrant further 
discussion. In terms of nursing demand, the political ambition to integrate health and social care and operate a seven-day week service has driven up staff demand. Additionally, the demographic change of an ageing population, living longer with complex health needs has exacerbated the requirement for higher numbers of appropriately skilled nurses.

In 2013 Robert Francis chaired a public inquiry into the prevalence of poor care and high death rates between January 2005 and March 2009 at Mid Staffordshire NHS Foundation Trust, a large public acute hospital in the UK (Francis, 2013). The report made 290 recommendations covering a wide range of areas including:

- transparency and openness throughout the health care system, fundamental standards for health care providers

- improved support for compassionate caring and committed care and stronger health care leadership.

There was a specific recommendation that adequate staff/patient ratios were implemented and monitored; this has resulted in increased staffing levels in some trusts and driven up demand for qualified and skilled nursing staff.

Nursing workforce demand could have been ameliorated through comprehensive workforce planning, inclusive of NHS, social care and independent care providers. However, there will always be unforeseen factors, such as the Mid Staffordshire inquiry, and it is imperative that workforce planning is sufficiently flexible to account for the outcomes of these unexpected events. Further, these factors are occurring at a time when the number of nurses working outside the NHS in the social care and independent sectors is also in deficit, and subsequently each sector is competing for the same staff resource as the NHS, negatively affecting the supply-demand equation. The supply of nursing staff is influenced by multiple factors, including student nurse commissions and the ageing workforce profile. 
Student nurse commissions have failed to keep pace with demand due to a number of influences, both historical and current. Traditionally, centralised workforce planning has dictated student nurse recruitment numbers, however, this is based on historical data and funding levels, and the figures did not always accurately reflect demand, often leading to a shortfall. Currently we are moving into a new era; bursaries were abolished in September 2017 and replaced by student loans, and each teaching institution is now responsible for determining student nurse numbers. Nevertheless, because the policy has only recently been implemented its impact cannot be measured for the foreseeable future, and the current shortfall remains.

The nursing workforce profile is ageing to the point where this has become a critical factor in determining nurse supply (Christie \& Co, 2015). In just over a decade, nurses over the age of 50 have risen from approximately $20 \%$ of the workforce in 2005 to nearly $30 \%$ in 2015 (Addicott, Maguire, Honeyman, \& Jabbal, 2015). Almost one in three nurses will be eligible to retire during the next 10 years and should this cohort of nurses take up the opportunity to retire there will be a significant loss of skills and experience. Consequently, it is imperative to develop mechanisms to promote the retention of the nursing workforce, particularly new registrants because leaving rates are highest amongst the younger and older age cohorts, with stress and burnout key predictors of intention to leave (Coomber \& Barriball, 2007).

As previously mentioned, in England the central collection of nursing data ceased in 2010, and although NHS digital has begun publishing vacancy statistics these are based on job advertisements listed on the NHS job website as opposed to the actual number of vacant posts within the NHS. The data regarding actual vacancy rate is difficult to obtain and complex because there is no standardised reporting mechanism for vacancies. However, there appears to be a general upward trend in the number of vacancies, and the NMC reported the vacancy rate for registered nurses in England doubled between 2013 and 2016, from 20,000 to nearly 40,000 posts (Royal College of Nursing, 2017a) 
Data from NHS Digital show that in any one year, approximately $10 \%$ of registered nurses and health visitors will leave the NHS, see Table 1 below. The table also highlights that despite the rising number of staff joining the NHS during the past five years, the number of leavers has also risen, and at a higher rate. This has led to a deficit in staff numbers at a time when there is increasing demand for nurses in the NHS to meet the growing population needs.

\section{Insert Table 1 in here}

Further, the NMC reported that more people are leaving the NMC register than joining; in September 2017 the gap was 27\% (Royal College of Nursing, 2017b). This has been exacerbated by the number of European Union nurses who have left in the past year, post the UK's decision to leave the European Union, but the change is not solely attributable to this group, see Table 2 below.

\section{Insert Table 2 in here}

Amongst newly qualified nurses turnover rates are high in the first year, and in some cases increase even further in the second year after qualification before declining thereafter (Health Education England, 2014). In the current climate, retention is a critical determinant of the supply-demand equation particularly when commissioned places for student nurse training have failed to keep pace with demand. Coupled with this, new registrants are most likely to leave the profession within two years of qualifying particularly if the organisation fails to provide adequate support and reduce exposure to high levels of stress (Health Education England, 2014). 
Formal support mechanisms like preceptorship, which provide a framework to scaffold staff's confidence and competence, improve the retention of newly qualified staff and are a valuable method of supporting the transition of new staff (Al-Dossary et al., 2014; Fiedler, Read, Lane, Hicks, \& Jegier, 2014; Kumaran \& Carney, 2014; Whitehead et al., 2013). Additionally, organisations that offer preceptorship programmes may benefit because of the increased continued professional development and greater engagement with the organisation that these programmes confer, thereby enhancing retention (Fiedler et al., 2014). Nevertheless, despite the evidence demonstrating the positive impact preceptorship programmes have on newly qualified staff attrition, there is little available evidence of measurable impacts.

\section{METHODS}

The study design employed mixed methods, gathering both qualitative and quantitative data, and aimed to:

- Review current preceptorship programmes within North West England NHS trusts, and ascertain the impact of these programmes on retention of newly qualified nurses and midwives.

- To make recommendations for a generic preceptorship framework.

The project framework comprised two stages, using online questionnaires and content analysis of preceptorship documentation from North West UK NHS trusts. This study utilised the SQUIRE (Standards for Quality Improvement Reporting Excellence) guidelines to ensure completeness and transparency of reporting, see Supplementary File 1.

A central tenet of the project's design and its innovation was the implementation of co-design with key stakeholders, which involved representatives from across the North West geographic health footprint, including preceptorship leads, preceptors, preceptees, educational managers, 
a newly qualified staff nurse and representatives from HEE North West region. This inclusive approach ensured that the voice of the practitioner was heard and stakeholders aspired to embed cultural change and foster sustainability. In addition, three conference events delivered throughout the project journey provided opportunities for networking and input into the development of a preceptorship framework.

\section{Stage 1:}

An online questionnaire was developed by the researchers, using Bristol Online Survey (BOS) software, to build a picture of current preceptorship programmes in North West NHS trusts. The questionnaire comprised eighteen questions and was devised based on the standards for preceptorship (Health Education England, 2015). These standards set out a list of key indicators designed to guide, not mandate, English trusts in the formation and monitoring of preceptorship programmes. The questionnaire was designed to enable benchmarking of current preceptorship programmes against key elements of the standards, including:

- Provision of a preceptorship programme and policy documents

- Identification and inclusion of newly qualified nurses and midwives in the programme

- The structure and time available to complete the preceptorship programme

- Monitoring and tracking of the preceptees and costs

- Attrition rates of nurses and midwives

- Training and development of preceptors to provide preceptorship

The questionnaire was an information gathering tool, seeking numerical data and free text responses to allow for further explanation. The data collection tool was piloted with five staff 
responsible for overseeing education within NHS trusts, and revised in line with their suggestions.

\section{$\underline{\text { Recruitment and sampling }}$}

HEE provided a list of all NHS trusts in the North West region, comprising 43 trusts. Trusts were excluded from the distribution list if they did not employ newly qualified nurses or midwives, e.g. ambulance service trusts and after applying these exclusion criteria, the final sample comprised 41 trusts. The Director of Nursing from each of these trusts was contacted by email, and asked to complete the questionnaire. If they did not respond, an alternative contact was requested, and reminders issued if no response was received.

\section{Data Analysis}

Data were exported from the BOS software into Statistical Package for Social Sciences (SPSS version 22) and analysed using descriptive statistics (frequencies and percentages) to illustrate the current situation with respect to preceptorship programmes in North West NHS trusts.

\section{Stage 2:}

As part of the questionnaire, trusts were asked to return documentation relating to their preceptorship programme. The preceptorship policy and framework were requested from each of the 41 eligible trusts, and the documents were sent electronically or in paper copy.

An inductive content analysis (Elo \& Kyngäs, 2008; Wildemuth, 2016) of the documentation was undertaken to explore the content, aims, philosophy and learning outcomes of the programmes to ascertain best practice models. Content analysis is a method of analysing, written verbal or visual communication messages (Cole, 1988; Neuendorf, 2016). It is a systematic and objective means of describing and quantifying phenomena and is a process whereby replicable and valid instances are drawn from the data with the expressed purpose 
of utilising this knowledge to design and guide new ways of working (Elo \& Kyngäs, 2008). To enable this process a pro forma was developed based on the national preceptorship standards and key performance indicators (developed by HEE), and analysis was undertaken using a cyclical iterative process as depicted in Figure 1.

\section{Insert figure 1 in here}

Researcher 1 , who is an experienced educationalist/nurse at the University analysed the documentation with the pro forma, using personal experience and knowledge to become immersed in the data and undertake the initial review. This enabled comparison of the documentation against the standards. The pro forma was amended and further developed as the database of documents increased. Once the initial reading was complete and saturation reached, the second reviewer, Researcher 2, an experienced researcher at the University, read the documents using the final pro forma; on completion of the second reading any minor alterations and additions were made to the pro forma, and a last reading of the documentation was made against the final pro forma and the findings from each reviewer integrated. This process of review fostered critical debate promoting validity and rigour.

\section{Ethical considerations}

As a data gathering and analysis exercise, this study was evaluative in origin. Therefore, according to Health Research Authority guidance ethical approval was not required for these stages of the study. 


\section{RESULTS}

\section{Stage 1: Quantitative Online Questionnaire}

Forty-one trusts were asked to take part in the study, and of these 23 completed the questionnaire giving an overall response rate of $56 \%$. The response rate to the questionnaire was higher in the smaller trusts ( $<1000$ qualified nursing, midwifery \& health visiting staff), although fewer of these trusts submitted preceptorship documentation for review. Conversely the response rate to the questionnaire was lower in the larger trusts, yet a greater number of preceptorship documents were received, see table 3.

Insert table 3 here

\section{$\underline{\text { Current preceptorship programmes and trust policies }}$}

Of the 23 responding trusts, 21 reported having a current preceptorship programme for newly registered nurses and midwives. Two trusts stated they did not have a preceptorship programme for newly registered nurses and midwives. However, one of these said they were currently looking into the situation because they had an increase in the number of preceptees joining the trust, and the other said theirs was not a formal programme, see Table 4.

Thirteen of the 23 trusts reported having a preceptorship policy, however, of those without a policy, four said their policy was in the process of being drafted, and six stated they had guidelines, a framework or other policies to address staff training. 
Of the ten trusts who said they did not have a policy; four were currently in the process of drafting a policy; five had either a framework or guidelines; and one had other policies that addressed staff induction and training needs, but was considering the introduction of a preceptorship policy in the future.

It is interesting to note that although only 13 trusts stated that they had a preceptorship policy, 18 trusts sent through their preceptorship documentation, containing details of a preceptorship policy. Therefore, there seems to be a lack of clarity about what is classed as a policy and what is classed as a framework or guidelines.

Fifteen trusts delivered multi-professional preceptorship programmes, including for example health visitors and allied health professionals, whereas eight trusts delivered their preceptorship programmes exclusively to nurses and midwives.

Identification of preceptees in the trust

Identification of staff to whom preceptorship training was offered was mostly achieved during the recruitment process, or post recruitment via the HR department, however, this was often on an ad hoc basis, as is reflected the responses below:

'HR currently have no way of knowing who is a preceptee on the job application. This is under review. At present we find out at induction who is a preceptee'

Trust $A$

‘dentified locally by Ward Manager and area Clinical Skills Trainer and entered onto programme' 
An alternative model utilised in some trusts was to offer preceptorship to all new employees.

'All newly appointed practitioners are offered access to preceptorship, regardless of whether they are newly qualified or not. This is to facilitate access to our inhouse educational programmes as well as to ensure support is offered during that transitional phase, in line with NMC recommendations.'

Trust $C$

Support for preceptees within the trust

Overall $78 \%(n=18)$ of responding trusts offered preceptees support through an induction, $57 \%$ $(n=13)$ offered study days, and $96 \%(n=22)$ provided preceptees with a named preceptor. However, $87 \%$ of trusts offered more than one type of support to their preceptees, see table 5.

Insert table 5 in here

\section{Monitoring and evaluation}

Trusts were also asked about monitoring and tracking of preceptees, and evaluation of the preceptorship programme within their trust. All responding trusts reported monitoring their preceptees, although the methods used varied between trusts and included:

- Monitoring by database: completed on an ongoing basis and held centrally

- Monitoring by managers: completed at a local level, not necessarily centralised 
- Completion of questionnaires, which were self-completed questionnaires regarding completion of preceptorship, and the onus was on the preceptee to complete the information.

Of the trusts, $52.2 \%$ evaluated their preceptorship programme, mostly through the use of paper based or online questionnaires, and approximately half $(47.8 \%)$ reported that they did not formally evaluate their preceptorship programme. The reasons given for not conducting evaluations were mainly focussed on a lack of process and guidance, for example:

"The programme is implemented locally following the guidance in the framework so there is no overarching system to monitor its effectiveness"

Trust $D$

Nevertheless, there was a general recognition that this was an area that needed to be addressed in the future:

"Current processes are informal and will be more structured in the new policy"

Trust $E$

\section{Cost of the preceptorship programme}

We requested information regarding the cost of each trust's preceptorship programme. However, of the trusts who responded 16 were unclear about the cost of their preceptorship programme, or how much additional funding they received from HEE North West for each preceptor. Some trusts recognised they were given funding, but did not know how this was used; some believed it was taken into the larger HR budget for the trust. Seven trusts offered 
a financial figure, but only one of these was commensurate with the funding offered by HEE North West at that time.

\section{$\underline{\text { Recruitment data }}$}

Fourteen trusts provided recruitment data for newly qualified nurses, and the remaining nine trusts did not provide any data for this question (it is not known if they were unwilling to share the data, or it was not collected by the trust). There was considerable variation in the numbers of newly qualified nurses recruited in the responding trusts, and within each trust there was variation across the different years. Trusts were also asked to provide their attrition rates for all nurses and midwives, and also newly qualified nurses and midwives, and again there was wide variation between trusts and across years. Trusts were also asked for figures on their newly qualified nurse and midwife attrition rates, however, only two trusts were able to provide this information, which highlights the under monitoring of attrition rates in many NHS trusts. It was impossible to disaggregate any meaningful findings from these data.

\section{Preceptor development and training}

The final part of the questionnaire covered the development and training of preceptors to deliver preceptorship within the trusts. Twenty-one trusts had a named preceptorship lead in place, who provided a point of contact for preceptees and preceptors. However, in terms of development and training across the region only 10 trusts offered training to their preceptors, and 13 reported they did not offer training. All the training was delivered in-house by the trusts. Two trusts utilised money from cash allocation and continuous professional development funding for this training, seven had no additional budget, and the remaining trust did not respond to this question. The preceptor training offered by trusts was predominantly one day in length, or less, with only three trusts offering more extensive training. There was a lack of 
standardised training or education for the preparation of preceptors to undertake the role, and less than $50 \%$ of trusts provided any details of preceptor development programmes.

\section{Stage 2: Content analysis of documentation}

Eighteen trusts returned documents relating to their preceptorship programmes. Of these 18, 13 trusts also supplied the accompanying preceptorship policy or procedure. These documents were used to build a picture of current trust preceptorship programmes. There was a wide variation in the documents received with no one standardised approach to the content, style or format. Naturally, each trust will have its own style and programme content depending on the trust's priorities and focus, however, there were a number of key areas or components, which were generic to preceptorship that could be more widely applied. These are discussed below.

\section{MultipRofessional POLICY}

The research identified the importance of an effective and well-written organisational policy to accurately inform the development and delivery of a successful preceptorship programme. We noted that where there were robust policies, there were strong preceptorship programmes, which highlights the essential link between policy and practice.

The research identified a number of benefits to having a formalised policy, including providing direction and ensuring consistency of standards and performance. A clear framework for delegation assisted staff decision making, and consequently promoted confidence around how preceptorship should be implemented and managed. This was particularly helpful in atypical situations, for example, where a preceptee is failing to make progress or meet set standards. 


\section{INDUCTION/ORIENTATION}

Our findings highlighted the differing models of staff recruitment into organisations. We recognised that some organisations will have very small numbers of new recruits, for example, one per month, whereas large organisations may be inducting staff on a cohort basis, with as many as 60 staff per iteration. Clearly, this influenced the model of preceptorship that is most suitable for each individual organisation. Further, the type of organisation, for example, primary care, secondary care, specialist services such as cancer or forensic mental health, will impact on the structure, content and delivery of preceptorship.

\section{PORTFOLIO}

The findings from the research identified an effective method to capture evidence of learning, assessment and successful preceptorship sign-off, which was through the completion of a portfolio. The portfolio should be designed to be flexible to meet the needs of both the preceptee and the organisation, using a range of evidence including self-assessment tools, skills logs, reflective practice and effective planning. Guidance from the relevant professional bodies should be included accordingly to enable fulfilment of CPD and/or re-registration requirements. Ongoing feedback is essential to ensure the usefulness of the portfolio and confirm it remains relevant to both the preceptee and the organisation.

\section{MONITORING AND EVALUATION}

One of the key gaps identified by the research was the absence of a consistent and robust approach to monitoring and evaluation of preceptorship in a large proportion of organisations. Trusts were failing to evaluate the pedagogical rigor of their programme, and also failing to 
address the strategic impact these initiatives may have on retention. Additionally, there was some confusion between audit, monitoring and evaluation.

It is imperative to evaluate the preceptorship programme because this would provide insights into the pedagogical effectiveness and strategic impact, if any, on retention, and there were a small number of examples of this within the data. Given that preceptorship is only one approach employed to improve staff retention, there are a number of aspects to consider when designing a monitoring and evaluation strategy. However, a robust and strategic approach to evaluation of the preceptorship framework and the impact of this on retention more widely is important.

Recognising this is a multifactorial and complex area, incorporating both strategic and operational aspects, it is important to consider carefully the key information to be gathered, by whom, from where and when, and the governance of this process. Further points to consider include:

- The robust evaluation of the preceptorship programme to ensure ongoing fitness for purpose.

- Re-interviewing preceptees after, for example, one year, to ascertain how preceptorship has promoted acculturation in the organisation. This information could be correlated with the statistics on retention and attrition to benchmark preceptorship against other retention strategies.

- Detailed capture and breakdown of information on attrition rates, including gender, age, profession, reasons for leaving the organisation, next destination etc. This facilitates better targeting of the preceptorship programme.

\section{DISCUSSION}


Four key themes emerged from the findings: the need for a flexible preceptorship framework, the dearth of information on workforce attrition rates, the need to enhance the formal evaluation of preceptorship programmes and the requirement for preceptor training initiatives. These are discussed in more detail below.

There was no one framework that could be universally applied across all trusts because the context and nature of each trust varies. Specialist trusts, for example, forensic mental health, cancer care or community trusts, have very different needs to acute trusts, and therefore may require bespoke programmes to meet the needs of their staff. This led to wide variation in content, and no particular core offering across trusts. Further, there was considerable difference in the size and timing of new registrant cohorts. For example, large acute trusts had intakes of new starters in excess of 30 biannually, whereas smaller trusts may take in one or two new starters at infrequent intervals across the year. This impacts on the ability to deliver a structured, multi-professional induction programme.

Attrition rates were not uniformly monitored and recorded across trusts, leading to a lack of clarity with respect to the wider attrition picture across the region. This is consistent with the consensus in the literature highlighting a lack of robust or systematic monitoring of attrition nationally across the NHS. This also meshes with the literature regarding the inadequacy of current workforce planning in addressing the sector as a whole, and the omission of social care nurses and independent sector nurses in the planning figures, resulting from a lack of strategic oversight. We recognise this as an area for further development and acknowledge the difficulties in collecting data in this area; however, it is imperative that the problem is addressed holistically in order to meet the demand for nurses across the sector.

Where the procedure or policy clearly articulated the boundaries of the preceptorship framework, this positively impacted on the programme. Trusts in which the policy provided a clear strategic direction enhanced the operationalisation of the preceptorship programme. The absence of a strategic framework in preceptorship has led to a lack of clear planning in local 
preceptorship programmes. We noted a dearth of reported evaluation for preceptorship programmes, although there were some excellent examples in a small number of trusts. Understanding local preceptorship programmes is vital to ensure that the evidence can be utilised to identify strengths and weaknesses and build on these where possible. This enables the trusts to continually develop their preceptorship programmes and enhance the provision of support for newly qualified nurses and midwives.

Our research highlighted the lack of preceptor training in trusts, and although we did not set out to investigate the role of the preceptor this became an emerging theme as the study evolved and was, therefore, of note. The literature has identified preceptor training as an area of weakness in many organisations, and there has been considerable discussion regarding the preparation and training for the role of preceptor (Muir et al., 2013; Panzavecchia \& Pearce, 2014). Because the preceptor plays a pivotal role in the transition of newly qualified members of staff from novice to expert, a well-functioning preceptee-preceptor relationship should support professional growth (Kaihlanen, Lakanmaa, \& Salminen, 2013). Further, as a preceptor can help to facilitate socialisation in the workplace, her/his capability in the role can have a major impact on preceptees sense of belonging (Phillips et al., 2014). The Department of Health identified 13 attributes of an effective preceptor (Department of Health, 2010) and these form a good framework on which to build, however, it is important to note that not all nurses will be well suited to the role of preceptor, and that being a good mentor does not inherently make you a good preceptor. In addition, the role of a preceptor should be recognised as having a separate identity, and therefore be given the recognition, time and preparation required.

However, the body of evidence regarding preceptor training in practice is weak (Panzavecchia \& Pearce, 2014; Walker, Earl, Costa, \& Cuddihy, 2013), and this was reflected in our research. There was scant evidence of formal preceptor training in the surveyed trusts, and often mentorship training was considered sufficient to produce preceptors. However, the roles are 
not identical, despite considerable overlap, and we would suggest this is an area that could be strengthened in many of the trusts.

\section{CONCLUSIONS}

This study identified the wide range of preceptorship initiatives across the North West region, and highlighted the lack of standardised programme content. Although not essentially a fundamental issue, this study has emphasised there are key components required for a successful preceptorship programme: multiprofessional policy, induction/orientation portfolio and a robust system of monitoring and evaluation.

With reference to these key components, we would suggest the preceptorship policy is essential. Policies are clearly an integral part of any effective, professional organisation and they provide the link between organisational strategy and operational management.

Consequently, these are the roadmap for developing and informing models of working, and without policies organisations are at risk of being unfocussed and lacking clarity, and this can lead to inconsistent decision making.

The wider strategic approach to preceptorship implementation, which communicates a clear vision and is practice focused, facilitates the ongoing development of new registrants from students to qualified practitioners. Preceptorship is one retention initiative that is important to arrest attrition and it may help to re-balance the supply-demand equation of nursing staff, and in so doing should impact positively on the organisation and service delivery. 


\section{RELEVANCE TO CLINICAL PRACTICE}

The significant shortage of nursing staff in England is an ongoing issue, exacerbated by the changing demographic of both the general population, and the nursing workforce. Recruitment and retention are key to ameliorating the shortfall, and formal support mechanisms like preceptorship, which provide a framework to scaffold staff's confidence and competence, can improve the retention of newly qualified staff. This should impact positively on the organisation and service delivery and help to re-balance the supply-demand equation of nursing staff. Understanding current preceptorship programmes is an important first step in establishing the fundamental building blocks of successful preceptorship programmes and enabling the sharing of exemplary good practice across organisations

Further research in this area would be enhanced by greater clarity in the available NHS data. It is currently problematic accessing detailed figures regarding the nursing workforce; a shift in policy is required in order to facilitate robust, transparent, accessible data. In the absence of this detail it becomes difficult to accurately understand the current context, and more importantly, strategically plan the future nursing workforce. The NHS, HEE, the Department of Health and Social Care and professional bodies, including the NMC need to adopt a more unified approach to workforce planning to achieve this.

It would also be beneficial to undertake research exploring whether the delivery of effective preceptorship programmes within organisations has a positive influence on rates of patient satisfaction, staff satisfaction and quality indicators, for example league tables. 


\section{REFERENCES}

Addicott, R., Maguire, D., Honeyman, M., \& Jabbal, J. (2015). Workforce planning in the NHS. The King's Fund.

Al-Dossary, R., Kitsantas, P., \& Maddox, P. J. (2014). The impact of residency programs on new nurse graduates' clinical decision-making and leadership skills: A systematic review. Nurse Education Today, 34(6), 1024-1028. doi:http://dx.doi.org/10.1016/j.nedt.2013.10.006

Chandler, G. E. (2012). Succeeding in the first year of practice: heed the wisdom of novice nurses. Journal for Nurses in Professional Development, 28(3), 103-107.

Christie \& Co. (2015). The UK Nursing Workforce Crisis or Opportunity? Retrieved from https://www.christie.com/christieMediaLibraries/christie/PDFs-Publications/Care/UKnursing-workforce.pdf

Cole, F. L. (1988). Content analysis: Process and application. Clinical Nurse Specialist, 2(1), 53-57.

Coomber, B., \& Barriball, K. L. (2007). Impact of job satisfaction components on intent to leave and turnover for hospital-based nurses: a review of the research literature. International journal of nursing studies, 44(2), 297-314.

Department of Health. (2010). Preceptorship Framework for Newly Registered Nurses, Midwives and Allied Health Professionals: Department of Health London.

Elo, S., \& Kyngäs, H. (2008). The qualitative content analysis process. Journal of advanced nursing, 62(1), 107-115.

Fiedler, R., Read, E. S., Lane, K. A., Hicks, F. D., \& Jegier, B. J. (2014). Long-term Outcomes of a Postbaccalaureate Nurse Residency Program: A Pilot Study. Journal of Nursing Administration, 44(7/8), 417-422.

Francis, R. (2013). Robert francis inquiry report into mid-staffordshire NHS foundation trust. The Stationery Office, London.

Hamshire, C., Spearing, R., \& Wibberley, C. (2014). Student \& Newly Qualified Staff attrition Scoping Review Final Report.

Health Education England. (2014). Growing Nursing Numbers. Retrieved from https://www.hee.nhs.uk/sites/default/files/documents/Growing\%20nursing\%20numbers\%2 0\%E2\%80\%93\%20Literature\%20Review.pdf

Health Education England. (2015). Health Education England Preceptorship Standards. Retrieved from https://www.fhft.nhs.uk/media/2601/hee-branded-preceptorship-standards-2015.pdf

Kaihlanen, A.-M., Lakanmaa, R.-L., \& Salminen, L. (2013). The transition from nursing student to registered nurse: The mentor's possibilities to act as a supporter. Nurse education in practice, 13(5), 418-422.

Kumaran, S., \& Carney, M. (2014). Role transition from student nurse to staff nurse: Facilitating the transition period. Nurse education in practice, 14(6), 605-611.

Marangozov, R., Williams, M., \& Buchan, J. (2016). The labour market for nurses in the UK and its relationship to the demand for, and supply of, international nurses in the NHS. Brighton: Institute for Employment Studies.

Migration Advisory Committee. (2016). Partial Reveiw of the Shortage Occupation List: Review of nursing. Retrieved from https://www.gov.uk/government/uploads/system/uploads/attachment data/file/510630/P artial review of the shortage occupation list - review of nursing.pdf

Muir, J., Ooms, A., Tapping, J., Marks-Maran, D., Phillips, S., \& Burke, L. (2013). Preceptors' perceptions of a preceptorship programme for newly qualified nurses. Nurse Education Today, 33(6), 633-638.

Neuendorf, K. A. (2016). The content analysis guidebook: Sage.

NHS Employers. (2015). NHS Registered Nurse Supply and Demand Survey Findings. Retrieved from Leeds:

Nursing and Midwifery Council. (2006). Preceptorship Guidelines. NMC Circular 21/2006. 
Panzavecchia, L., \& Pearce, R. (2014). Are preceptors adequately prepared for their role in supporting newly qualified staff? Nurse Education Today, 34(7), 1119-1124.

Phillips, C., Kenny, A., Esterman, A., \& Smith, C. (2014). A secondary data analysis examining the needs of graduate nurses in their transition to a new role. Nurse education in practice, 14(2), 106-111.

Royal College of Nursing. (2017a). Safe and Effective Staffing: the Real Picture. Retrieved from https://www.rcn.org.uk/-/media/royal-college-ofnursing/documents/publications/2017/may/pub-006195.pdf

Royal College of Nursing. (2017b). The UK nursing labour market review 2017. Retrieved from https://www.rcn.org.uk/-/media/royal-college-ofnursing/documents/publications/2017/december/pdf-006625.pdf

Rush, K. L., Adamack, M., Gordon, J., Lilly, M., \& Janke, R. (2013). Best practices of formal new graduate nurse transition programs: an integrative review. International journal of nursing studies, 50(3), 345-356.

Walker, A., Earl, C., Costa, B., \& Cuddihy, L. (2013). Graduate nurses' transition and integration into the workplace: A qualitative comparison of graduate nurses' and Nurse Unit Managers' perspectives. Nurse Education Today, 33(3), 291-296.

Whitehead, B., Owen, P., Holmes, D., Beddingham, E., Simmons, M., Henshaw, L., . . Walker, C. (2013). Supporting newly qualified nurses in the UK: A systematic literature review. Nurse Education Today, 33(4), 370-377.

Wildemuth, B. M. (2016). Applications of social research methods to questions in information and library science: $A B C-C L I O$. 
Stage 1: Initial reading of the documentation by practitioner to identify categories

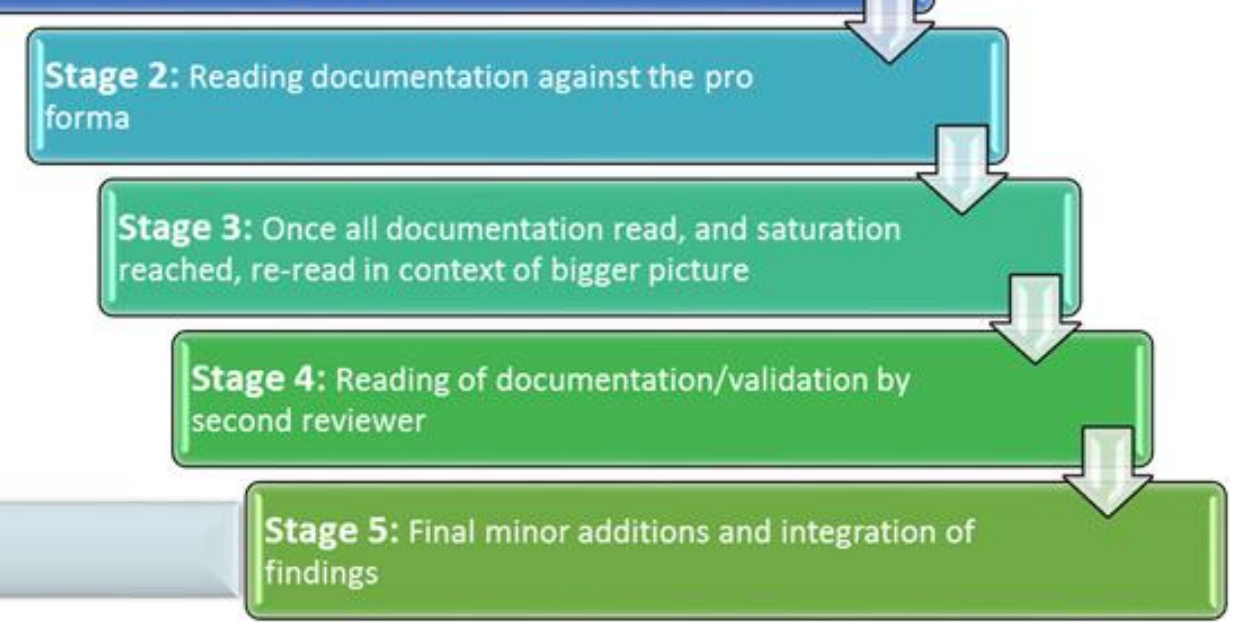

Figure 1 


\section{TABLES}

\begin{tabular}{|c|c|c|c|c|}
\hline \multicolumn{1}{|c|}{ Year } & Joiners & Leavers & $\begin{array}{c}\text { Number of } \\
\text { staff at start } \\
\text { of period }\end{array}$ & $\begin{array}{c}\text { Leavers as a } \\
\text { proportion of staff at } \\
\text { the start of the period }\end{array}$ \\
\hline $\mathbf{2 0 1 2 - 2 0 1 3}$ & 29,390 & 27,960 & 306,177 & $9.1 \%$ \\
\hline $\mathbf{2 0 1 3 - 2 0 1 4}$ & 31,618 & 30,581 & 308,783 & $9.9 \%$ \\
\hline $\mathbf{2 0 1 4 - 2 0 1 5}$ & 33,023 & 33,816 & 312,391 & $10.8 \%$ \\
\hline $\mathbf{2 0 1 5 - 2 0 1 6}$ & 32,628 & 32,822 & 315,139 & $10.4 \%$ \\
\hline $\mathbf{2 0 1 6 - 2 0 1 7}$ & 30,388 & 33,440 & 318,187 & $10.5 \%$ \\
\hline
\end{tabular}

Table 1: Registered nurse and midwife joiners and leavers 2012-2017

\footnotetext{
${ }^{\dagger}$ Source: NHS Digital, NHS Hospital \& Community Health Service (HCHS) workforce statistics
} 
$\underline{\text { TABLES }}$

\begin{tabular}{|l|c|c|c|c|}
\hline Year & \multicolumn{1}{|c|}{ UK } & EEA & Outside EEA & Total \\
\hline $\mathbf{2 0 1 2 - 2 0 1 3}$ & 20,878 & 1,240 & 2,074 & 24,192 \\
\hline $\mathbf{2 0 1 3 - 2 0 1 4}$ & 21,336 & 1,354 & 1,814 & 24,504 \\
\hline $\mathbf{2 0 1 4 - 2 0 1 5}$ & 22,094 & 1,743 & 1,684 & 25,521 \\
\hline $\mathbf{2 0 1 5 - 2 0 1 6}$ & 26,653 & 2,435 & 2,090 & 31,178 \\
\hline $\mathbf{2 0 1 6 - 2 0 1 7}$ & 29,019 & 4,067 & 2,277 & 35,363 \\
\hline \% change 2012-2017 & $39.0 \%$ & $228.0 \%$ & $9.8 \%$ & $46.2 \%$ \\
\hline
\end{tabular}

Table 1: Number of nurses and midwives, from different regions, leaving the NMC register 2012- 2017 


\begin{tabular}{|c|c|c|}
\hline $\begin{array}{c}\text { Number of qualified nursing, } \\
\text { midwifery \& health visiting staff in } \\
\text { trust }\end{array}$ & $\begin{array}{c}\text { Questionnaire } \\
\text { response rate }\end{array}$ & $\begin{array}{c}\text { Content analysis } \\
\text { response rate }\end{array}$ \\
\hline$<500$ & $67 \%$ & $33 \%$ \\
\hline $500-999$ & $67 \%$ & $44 \%$ \\
\hline $1000-1999$ & $53 \%$ & $42 \%$ \\
\hline$\geq 2000$ & $56 \%$ & $56 \%$ \\
\hline
\end{tabular}

Table 3: Response rate based on size of trust 


\section{$\underline{\text { TABLES }}$}

\section{Trust currently offers a preceptorship programme for newly registered nurses} and midwives
$91.3 \%(21)$ Yes
$8.7 \%(2) \mathrm{No}^{\dagger}$

Trust has a preceptorship policy
$56.5 \%(13)$ Yes
$43.5 \%(10) \mathrm{No}^{\ddagger}$

\section{Type of programme}

\section{$65.2 \%(15)$ Multiprofessional}

$34.8 \%(8)$ Nursing and midwifery

Table 4: Trust preceptorship programme and preceptorship policy

\footnotetext{
+ One of these trusts was currently exploring the development of a programme

* Four of these trusts were in the process of drafting a policy, and five had guidelines, a framework or other policies covering staff training
} 


\section{TABLES}

\begin{tabular}{|l|l|l|l|l|l|}
\hline $\begin{array}{l}\text { Preceptorship } \\
\text { element }\end{array}$ & Induction & $\begin{array}{l}\text { Preceptorship } \\
\text { programme }\end{array}$ & $\begin{array}{l}\text { Study } \\
\text { Days }\end{array}$ & $\begin{array}{l}\text { One-to-one } \\
\text { time with } \\
\text { preceptor }\end{array}$ & Other \\
\hline Protected time (18) & - & 12 & 11 & 14 & 5 \\
\hline $\begin{array}{l}\text { Non-protected time } \\
\text { (5) }\end{array}$ & 5 & 3 & 2 & 5 & 1 \\
\hline
\end{tabular}

Table 5: Protected time for preceptorship (note: some trusts offered more than one element) 